\title{
TET family proteins and 5-hydroxymethylcytosine in esophageal squamous cell carcinoma
}

\author{
Asuka Murata ${ }^{1, *}$, Yoshifumi Baba ${ }^{1, *}$, Takatsugu Ishimoto ${ }^{1}$, Keisuke Miyake ${ }^{1}$, Keisuke \\ Kosumi $^{1}$, Kazuto Harada ${ }^{1}$, Junji Kurashige ${ }^{1}$, Shiro Iwagami ${ }^{1}$, Yasuo Sakamoto ${ }^{1}$, \\ Yuji Miyamoto', Naoya Yoshida ${ }^{1}$, Manabu Yamamoto², Shinya Oda ${ }^{3}$, Masayuki \\ Watanabe ${ }^{4}$, Mitsuyoshi Nakao5${ }^{5}$, Hideo Baba ${ }^{1}$ \\ ${ }^{1}$ Department of Gastroenterological Surgery, Graduate School of Medical Science, Kumamoto University, Japan \\ ${ }^{2}$ Department of Surgery, National Hospital Organization Kyushu Cancer Center, Japan \\ ${ }^{3}$ Department of Cancer Biology, National Kyushu Cancer Center Clinical Research Institute, Japan \\ ${ }^{4}$ Department of Gastroenterological Surgery, Cancer Institute Hospital, Japanese Foundation for Cancer Research, Japan \\ ${ }^{5}$ Department of Medical Cell Biology, Institute of Molecular Embryology and Genetics, Kumamoto University, Japan \\ *These authors have contributed equally to this work
}

Correspondence to:

Yoshifumi Baba, e-mail: y-baba@kumamoto-u.ac.jp

Keywords: epigenetics, markers, demethylation, TET

Received: April 17, $2015 \quad$ Accepted: May 26, $2015 \quad$ Published: June 08, 2015

\section{ABSTRACT}

Mammalian DNA is epigenetically marked by $5^{\prime}$-cytosine methylation (5-methylcytosine [5-mC]). The Ten-eleven translocation (TET) enzymes (TET1, TET2, and TET3) are implicated in DNA demethylation, through dioxygenase activity that converts 5-mC to 5-hydroxymethylcytosine (5-hmC). Although decreased TET is reportedly associated with decreased $5-\mathrm{hmC}$ levels in various cancers, functions of 5-hmC and TET expression in esophageal squamous cell carcinoma (ESCC) are unclear. We used ELISA and immunohistochemistry tests to analyze 5-hmC status in ESCC tissues, RT-qPCR to analyze TET family mRNA expression in normal and tumor tissues, and pyrosequencing to quantify LINE-1 (i.e., global DNA methylation) levels. ELISA and immunohistochemical testing showed 5-hmC levels were significantly lower in ESCC than in paired normal tissues $(P<0.0001)$. TET2 expression was significantly lower in ESCCs than paired normal tissues $(P<0.0001)$, and significantly associated with 5-hmC levels in ESCCs $(P=0.003, r=0.33)$. 5 -hmC levels were also significantly associated with LINE-1 methylation level $(P=0.0002, r=0.39)$. Patients with low $5-h m C$ levels had shorter overall survival than those with higher levels, although not significantly so $(P=0.084)$. In conclusion, $5-\mathrm{hmC}$ expression was decreased in ESCC tissues, and was associated with TET2 expression level. TET2 reduction and subsequent 5-hmC loss might affect ESCC development.

\section{INTRODUCTION}

Esophageal squamous cell carcinoma (ESCC), the most common esophageal cancer in East Asian countries, is a very aggressive malignancy that requires combined modality therapies [1]. However, the limited improvement provided by conventional therapies has prompted us to seek innovative strategies for treating ESCC, especially molecularly targeted treatments. Importantly, epigenetic changes, including alterations in DNA methylation, are reversible, and can thus be targets for therapy or chemoprevention [2-6].

DNA methylation-conversion of cytosine to 5-methylcytosine (5-mC) - is a primary epigenetic mechanism involved in imprinting, X-chromosome inactivation, and repression of endogenous retroviruses. In human cancers, DNA methylation alterations include global DNA hypomethylation and site-specific $\mathrm{CpG}$ island 
promoter hypermethylation, which leads to genomic instability or altered gene expression [7]. The ten-eleven translocation (TET) family proteins can convert 5-mC to 5-hydroxymethylcytosine $(5-\mathrm{hmC})$, which is now widely recognized as the "sixth base" in the mammalian genome, following 5-mC, the "fifth base" [8-13]. 5-hmC is abundant in brain and embryonic stem cells, and is also distributed in many different human tissues [9, 10, 14, 15] Emerging evidence suggests that 5-hmC and TET family have unique functions in many processes such as gene control mechanisms and DNA methylation regulation, and affect many diseases, especially cancers. Loss of 5-hmC or TETs has been reported in several cancer types, such as myeloid leukemia, melanoma, and colorectal, breast, liver, and lung cancers [16-22]. However, no study has evaluated the status of 5-hmC and TETs expression in ESCC.

In this study, we examined the status of TETs and 5-hmC expression in matched ESCC and normal specimens, using ELIZA, immunohistochemistry (IHC) and RT-qPCR. We also quantified long interspersed nucleotide element-1 (LINE-1) methylation levels in these specimens, using pyrosequencing. As LINE-1 retrotransposons constitute a substantial portion of the human genome, LINE-1 methylation levels are regarded as surrogates for global DNA methylation [23]. Thus,

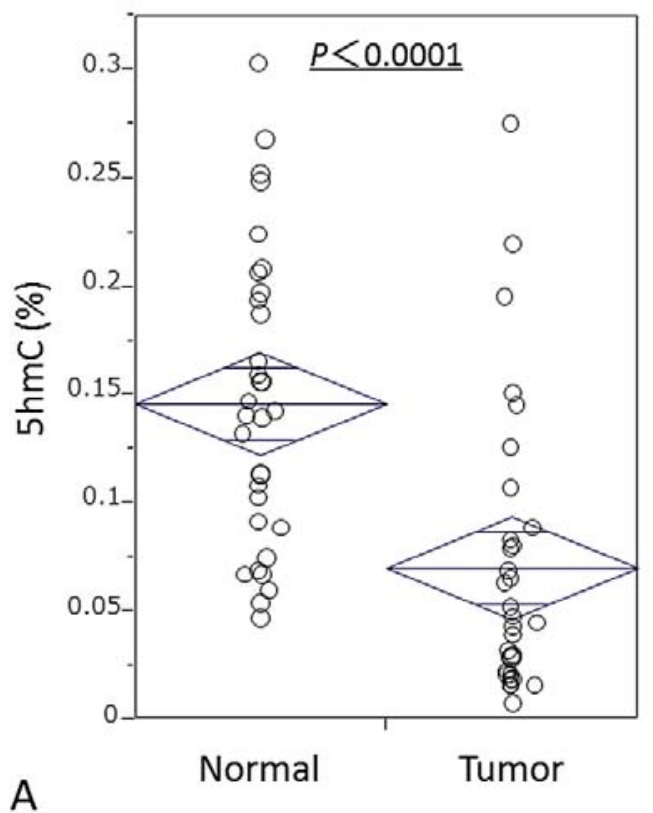

we could comprehensively evaluate relationships among TETs, 5-hmC and LINE-1 methylation in ESCCs. Finally, we examined the prognostic value of 5-hmC and TET expression in patients with ESCC.

\section{RESULTS}

\section{5-hmC expression in ESCCs and matched normal mucosa}

To evaluate differences of 5-hmC status between esophageal cancer cells and normal epithelial cells, we first examined the 5 -hmC content of nuclear DNA as $\% 5$-hmC level by ELISA assay in 33 matched ESCC-normal esophageal mucosa pairs. Cancer tissues had significantly lower levels of 5-hmC (median: 0.046; mean: 0.070; standard deviation [SD]: 0.07) than matched normal mucosa (median: 0.141; mean: 0.146; SD: 0.07; $P<0.0001$ by paired $t$-test) (Fig. 1A). Using 10 ESCC resected specimens, we confirmed by IHC that cancer cells had lower 5-hmC levels than did normal epithelial cells (Fig. 1B); nuclear cells of normal esophageal epithelial cells were immunoreactive for 5 -hmC, whereas most cancer cells were not.

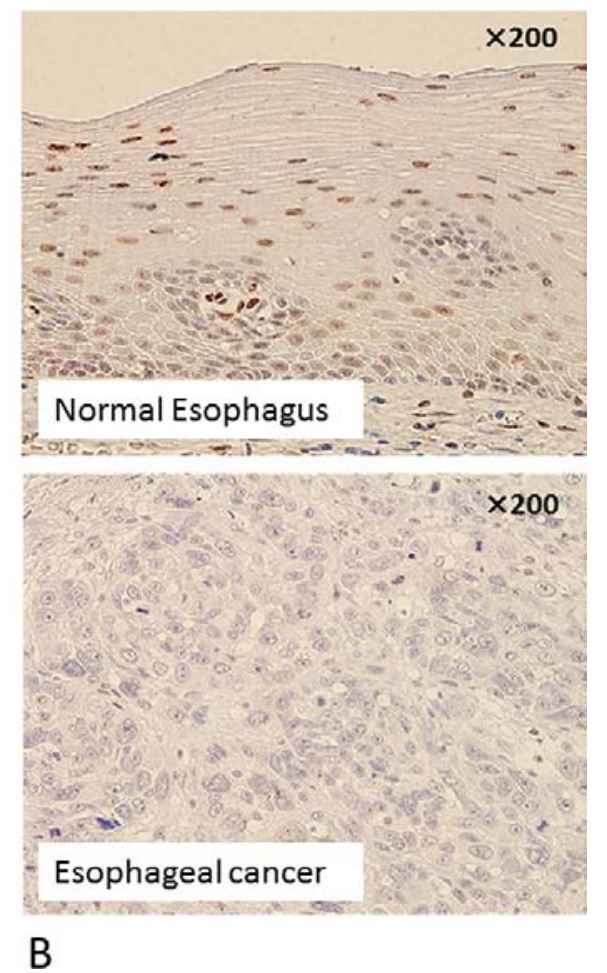

Figure 1: 5-hmC expression in ESCC. A. ELISA assay shows percentages of 5-hmC levels in 33 matched ESCC normal mucosa specimens. B. Immunohistochemical staining for 5-hmC in normal esophageal epithelium and ESCC. 


\section{TETs expression in ESCCs and matched normal mucosa}

We examined TET family mRNA levels in 32 ESCC specimens and matched normal esophageal mucosa utilizing frozen tissues in RT-qPCR assays. Levels of TET1 expression were similar between cancer tissues (median: 0.019; mean: 0.022; SD: 0.02) and normal mucosa (median: 0.015 ; mean: 0.018 ; SD: $0.01 ; P=0.23$ ) (Fig. 2A). Notably, cancer tissues had significantly lower TET2 levels (median: 0.045; mean: 0.053; SD: 0.03) than did normal mucosa (median: 0.087; mean: 0.090; SD 0.03; $P<0.0001$, paired $t$-test; Fig. 2B); and significantly higher TET3 levels (median: 0.030; mean: 0.037; SD: 0.032) than did normal mucosa (median 0.024; mean 0.026; SD 0.01; $P=0.0023$; Fig. 2C).

\section{TETs expression and 5-hmC level in cancer tissues}

We quantified the 5-hmC content of nuclear DNA as percentages of 5-hmC levels by ELISA in 95 ESCC specimens and obtained valid results in all cases, distribution of which over a $0-0.279$ range was mean: 0.049; median: 0.029; SD, 0.050; and interquartile range, $0.016-0.068$. We also evaluated expression levels of $T E T 1,2$, and 3 by RT-qPCR assay. We found that TET2 expression was significantly associated with 5 -hmC level $(P=0.003 ; r=0.33$ by paired $t$-test; Fig. 3B). However, TET1 and TET3 expression were not associated with 5-hmC level ( $P=0.306$ and $P=0.927$, respectively; Fig. 3A, 3C).

\section{LINE-1 methylation level and 5-hmC level or TETs expression in cancer tissues}

LINE-1 methylation level is accepted as a surrogate marker for global DNA methylation level. Pyrosequencing was used to quantify LINE-1 methylation (Fig. 4A) to examine relationships between LINE-1 methylation and 5 -hmC level or TET expression. We found 5-hmC levels were significantly associated with LINE-1 methylation $(P=0.0002 ; r=0.39$, paired $t$-test; Fig. 4B). However, TET mRNA expression was not associated with LINE-1 methylation (TET1: $P=0.517$; TET2: $P=0.050$; TET3: $P=0.946$ respectively, paired $t$-test; Fig. $4 \mathrm{C}-4 \mathrm{E})$.

\section{5-hmC levels and clinical, epidemiological, and pathological variables}

We assessed 5-hmC level against clinicopathological characteristics in 95 ESCCs, and found 5-hmC level was significantly associated with histologic grade $(P=0.017)$, but not with sex, age, year of operation, tobacco smoking,

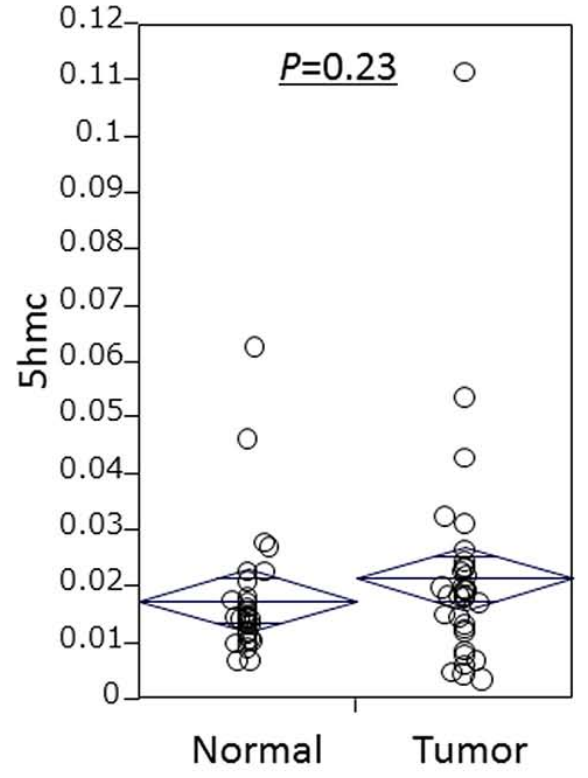

TET1

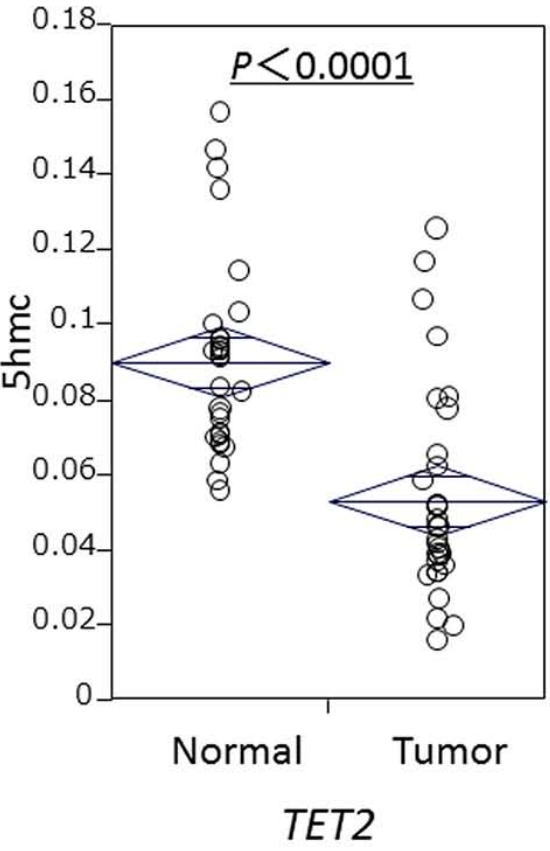

B

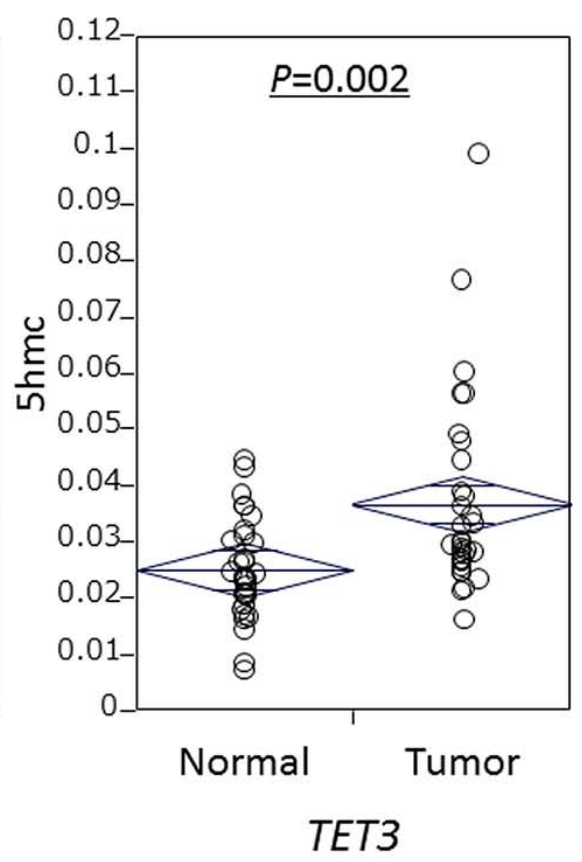

C

Figure 2: mRNA levels of TET family in 32 matched ESCC and matched normal mucosa specimens. A. TET1 expression. B. TET2 expression. C. TET3 expression. 

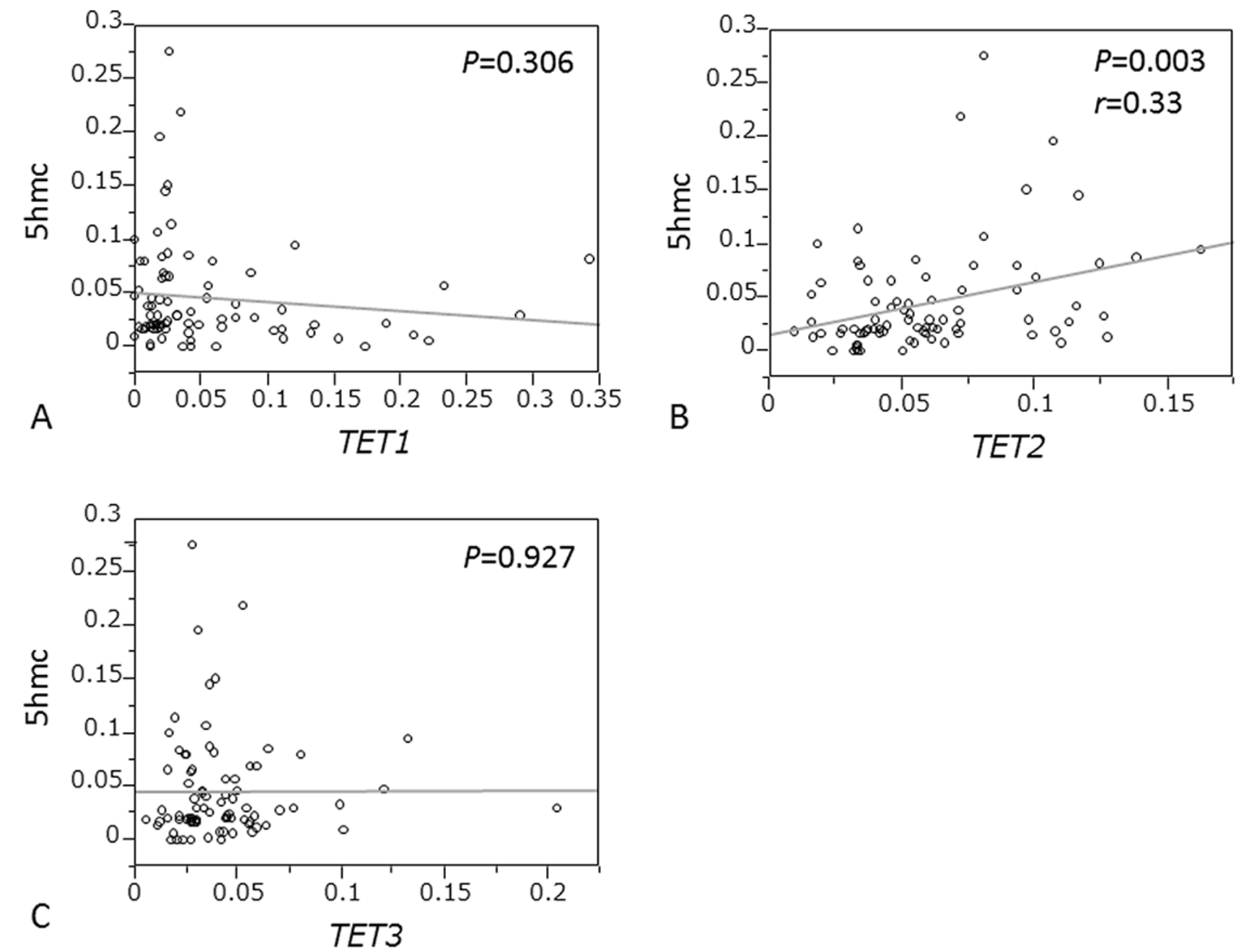

Figure 3: Correlation between 5-hmC expression and mRNA levels of TETs family in ESCC. A. TET1 expression. B. TET2 expression. C. TET3 expression.

alcohol drinking, preoperative chemotherapy, tumor location, stage, or lymph node metastases (all $P>0.078$; Table 1).

\section{TET2 expression and clinical, epidemiological, and pathological variables}

As TET2 expression was significantly associated with 5-hmC expression, TET2 may be more important in ESCC development than TET1 and TET3; we therefore evaluated relationships between TET2 and clinicopathological characteristics. Distribution of TET2 expression was mean: 0.060 ; median: 0.053; $\mathrm{SD}, 0.032$; range: $0-0.16$; and interquartile range: $0.034-0.075$. TET2 expression was not associated with sex, age, year of operation, tobacco smoking, alcohol drinking, preoperative chemotherapy, tumor location, stage, lymph node metastases, or histologic grade (all $P>0.215$; Supplemental Table).

\section{5-hmC and TET2 expression in ESCC and patient survival}

During an adequate follow-up period among the 95 patients, 46 patients died, including 26 deaths that were confirmed as attributable to ESCC. Median follow-up time for censored patients was 12.4 months. We divided patients into those who expressed high 5 -hmC levels $(\geq 0.029, n=48)$ and the low 5 -hmC group (0-0.028, $n=47$ ). The low 5 -hmC group experienced shorter overall survival than the high 5-hmC group, but not significantly so (log-rank $P=0.084$; univariate hazard ratio $=1.68,95 \%$ confidence interval (CI): 0.93-3.09, $P=0.086$ ) (Fig. 5A). When patients were divided into those who expressed high TET2 levels $(\geq 0.053, n=41)$ and low TET2 $(0.0059-0.0529, n=40)$, Kaplan-Meier analysis showed the two groups to have similar overall mortality rates ( $\log$-rank $P=0.38$; Fig. 5B). In addition, we found that TET1 and TET2 were not associated with patient prognosis ( $\log$-rank $P=0.39$ for $T E T 1$ and $P=0.95$ for TET3). 


\section{$\underline{\text { LINE-1 methylation level ; } 51}$}

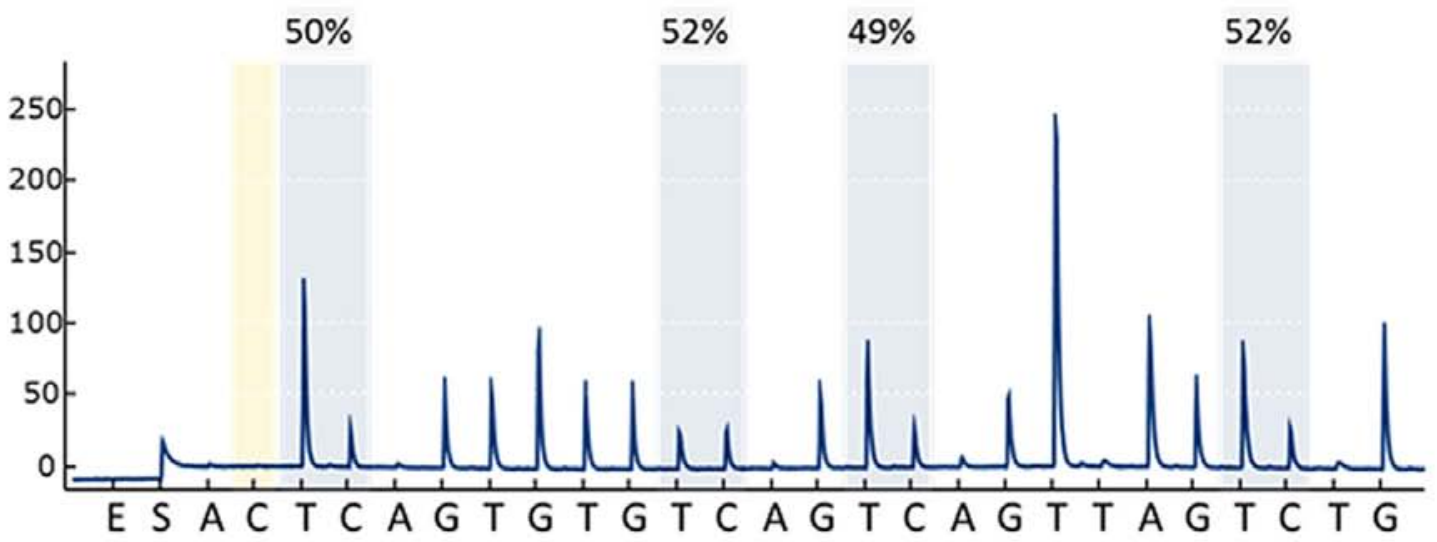

A
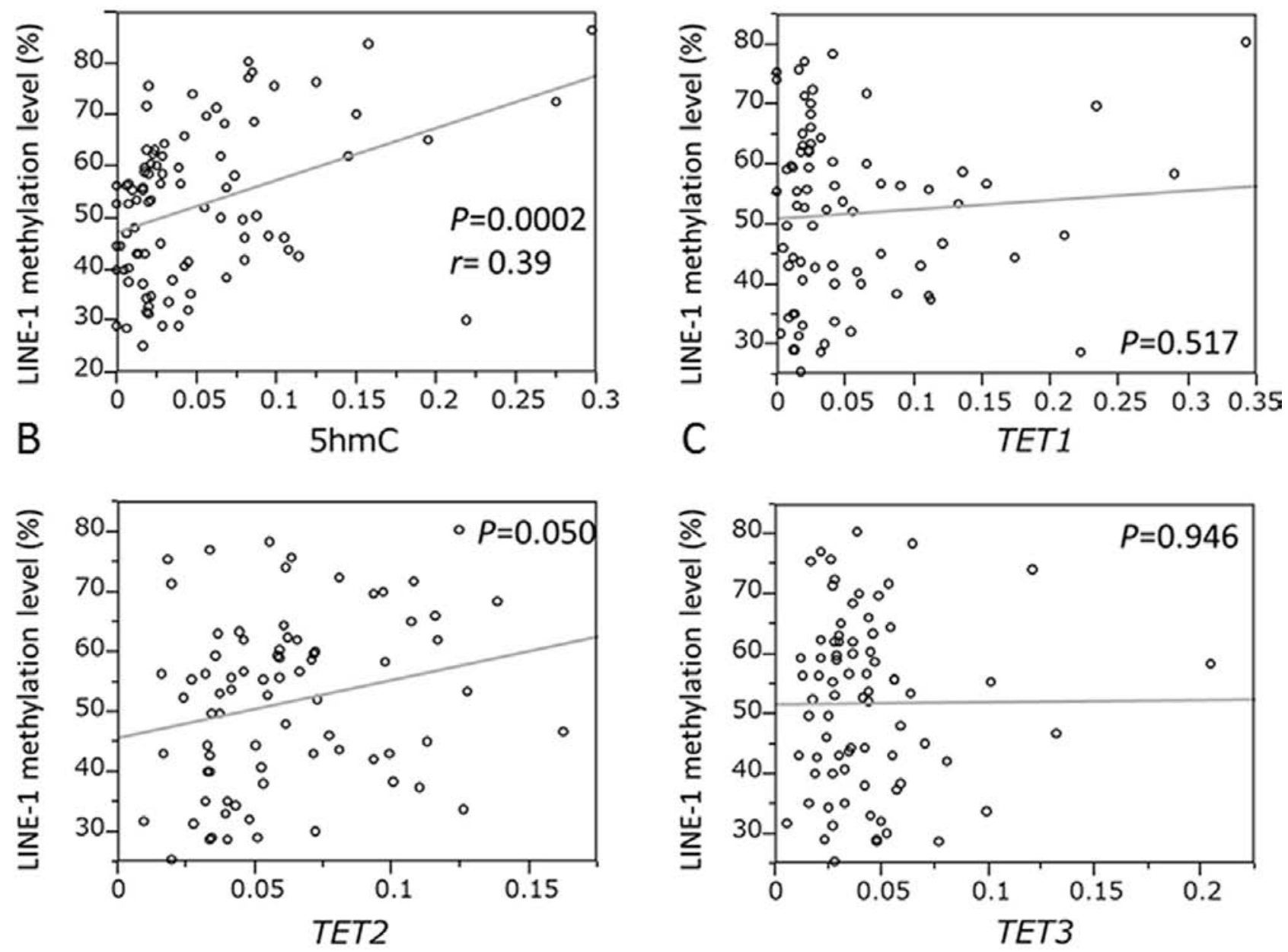

D

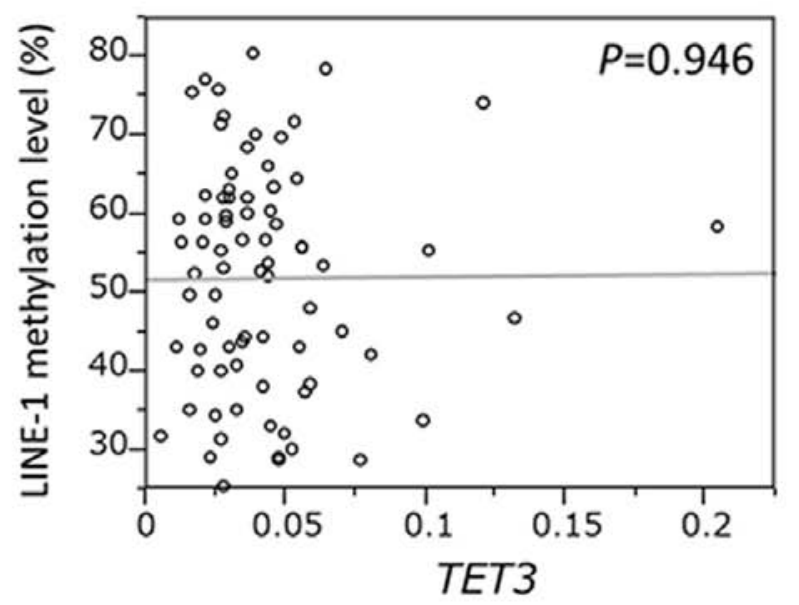

E

Figure 4: Correlation between the LINE-1 methylation levels and 5-hmC expression or mRNA levels of TETs family. A. Pyrosequencing for LINE-1 methylation level. B. Relationship between LINE-1 methylation level and $5 \mathrm{hmC}$ level. $(n=89$, $P=0.0002, r=0.39)$. C. Relationship between LINE-1 methylation level and TET1 expression. D. Relationship between LINE-1 methylation level and TET2 expression. E. Relationship between LINE-1 methylation level and TET3 expression. 
Table 1: Expression of 5-hmC in esophageal cancers, with clinical and tumor features

\begin{tabular}{|c|c|c|c|c|}
\hline \multirow{2}{*}{$\begin{array}{l}\text { Clinical, epidemiologic or } \\
\text { pathologic feature }\end{array}$} & \multirow[t]{2}{*}{ Total N } & \multicolumn{2}{|c|}{ 5-hmC expression (\%) } & \multirow[t]{2}{*}{$P$ value } \\
\hline & & high & low & \\
\hline All cases & 95 & 48 & 47 & \\
\hline Mean age \pm SD & $68.3 \pm 8.7$ & $67.8 \pm 8.1$ & $68.8 \pm 9.4$ & 0.56 \\
\hline Sex & & & & 0.08 \\
\hline Male & 86 (91\%) & $41(85 \%)$ & $45(96 \%)$ & \\
\hline Female & $9(9 \%)$ & $7(15 \%)$ & $2(4 \%)$ & \\
\hline Tobacco use & & & & 0.53 \\
\hline Yes & $81(85 \%)$ & $42(88 \%)$ & $39(83 \%)$ & \\
\hline No & $14(15 \%)$ & $8(12 \%)$ & $8(17 \%)$ & \\
\hline Alcohol use & & & & 0.16 \\
\hline Yes & $85(89 \%)$ & $45(94 \%)$ & $40(85 \%)$ & \\
\hline No & $10(11 \%)$ & $3(6 \%)$ & $7(15 \%)$ & \\
\hline Year of diagnosis & & & & 0.23 \\
\hline 2003 to 2007 & $14(15 \%)$ & $5(10 \%)$ & $9(19 \%)$ & \\
\hline 2008 to 2012 & $81(85 \%)$ & $43(90 \%)$ & $38(81 \%)$ & \\
\hline Preoperative treatment & & & & 0.24 \\
\hline Present & $38(40 \%)$ & $22(46 \%)$ & $16(34 \%)$ & \\
\hline Absent & $57(60 \%)$ & $26(54 \%)$ & $32(66 \%)$ & \\
\hline Tumor location & & & & 0.14 \\
\hline High & $9(9 \%)$ & $6(13 \%)$ & $3(6 \%)$ & \\
\hline Middle & $47(50 \%)$ & $19(40 \%)$ & $28(60 \%)$ & \\
\hline Low & $39(41 \%)$ & $23(47 \%)$ & $16(34 \%)$ & \\
\hline Stage & & & & 0.70 \\
\hline I (IA, IB) & $12(13 \%)$ & $6(13 \%)$ & $6(13 \%)$ & \\
\hline II (IIA, IIB) & $27(29 \%)$ & $13(28 \%)$ & $14(30 \%)$ & \\
\hline III (IIIA, IIIB, IIIC) & $53(57 \%)$ & $27(58 \%)$ & $26(57 \%)$ & \\
\hline Lymph node metastasis & & & & 0.60 \\
\hline Positive & $65(68 \%)$ & $34(71 \%)$ & $31(66 \%)$ & \\
\hline Negative & $30(32 \%)$ & $14(29 \%)$ & $16(34 \%)$ & \\
\hline Histologic grade & & & & 0.017 \\
\hline G1 & $29(31 \%)$ & $19(40 \%)$ & $10(21 \%)$ & \\
\hline $\mathrm{G} 2$ & $46(48 \%)$ & $24(50 \%)$ & $22(47 \%)$ & \\
\hline G3-4 & $20(21 \%)$ & $5(10 \%)$ & $15(32 \%)$ & \\
\hline
\end{tabular}



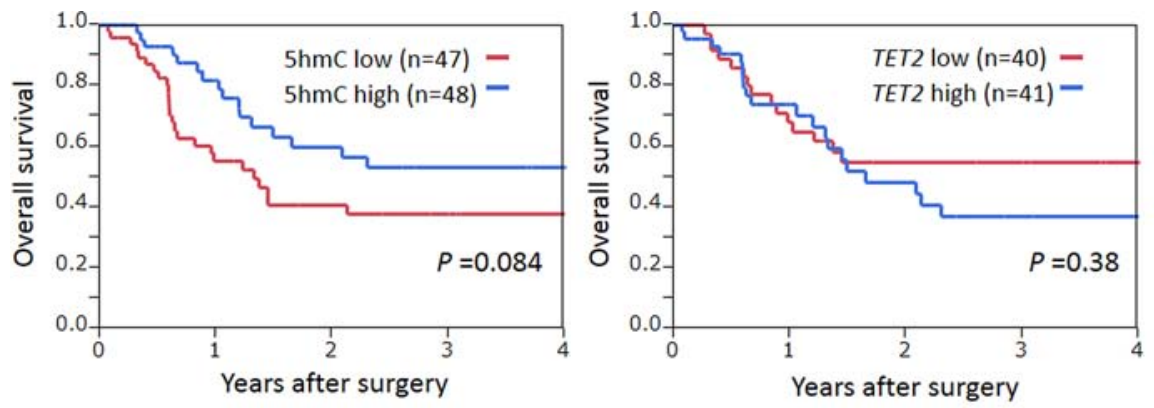

Number at risk
\begin{tabular}{|c|c|c|c|c|c|}
\hline Years & 0 & 1 & 2 & 3 & 4 \\
\hline $5 \mathrm{hmC}$ low & 47 & 28 & 18 & 14 & 11 \\
\hline $5 \mathrm{hmC}$ high & 48 & 21 & 13 & 10 & 7 \\
\hline
\end{tabular}

Number at risk
\begin{tabular}{|c|c|c|c|c|c|}
\hline Years & 0 & 1 & 2 & 3 & 4 \\
\hline TET2 low & 40 & 24 & 16 & 14 & 9 \\
\hline TET2 high & 41 & 20 & 12 & 8 & 7 \\
\hline
\end{tabular}

A

B

Figure 5: A. Kaplan-Meier curves for overall survival according to $5 \mathrm{hmC}$ status in ESCCs. B. Kaplan-Meier curves for overall survival according to TET2 stutus in ESCCs.

\section{Cytosine}<smiles>Nc1cc[nH]c(=O)n1</smiles>

$5 \mathrm{mC}$<smiles>Cc1c[nH]c(=O)nc1N</smiles>

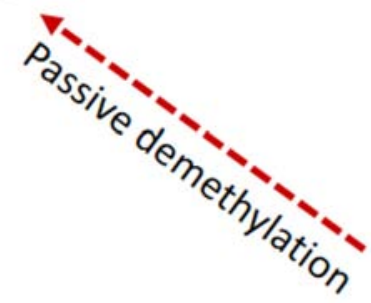<smiles>Nc1nc(=O)[nH]cc1CO</smiles>

$5 \mathrm{hmC}$

Figure 6: Model for the relationship between 5-hmC and TET2 in ESCC.

\section{DISCUSSION}

This is the first study to examine expression levels of TET family and 5-hmC in esophageal cancer. Although DNA methylation and its mechanism (e.g., the DNA-methyltransferase [DNMT] family) are wellstudied in human cancer, DNA demethylation is poorly understood. The TET family is apparently a key factor of DNA demethylation and can convert 5-mC to $5-\mathrm{hmC}$ in mammalian cells. Our current study found that esophageal cancer tissues expressed lower levels of 5-hmC and TET2 than did normal esophageal epithelium. Additionally, TET2 expression was significantly associated with $5-\mathrm{hmC}$ level in ESCCs, but TET1 and TET3 were not. Together, these results indicate that TET2 has a central function in converting $5-\mathrm{mC}$ to $5-\mathrm{hmC}$ in esophageal epithelial cells, and reduced TET2 causes decreased 5-hmC level in those cells, leading to ESCC development (Fig. 6). 
The discovery of 5-hmC and TET enzymes as DNA modifications and modifiers (respectively) in mammalian genomes has raised many questions on the function of DNA demethylation in epigenetic regulation. Apparently, 5 -hmC is not merely a marker, but has a mechanistic role in gene expression, $[9,31,32]$ such as alteration of chromatin structure or contribution to the recruitment or exclusion of DNA-binding proteins. 5-hmC prevents DNMT-1-mediated methylation of target cytosines [33], thus leading to active demethylation [34]. Damage to 5-hmC in methyl-CpG sequences interferes with the ability of several methyl-CpG-binding proteins to bind to them, which may affect transcriptional activity of genes with significant levels of promotor-region 5-hmC [21, 35]. In view of the possibility that disordered 5 -hmC plays a role in cancer development, better understanding of 5-hmC status is increasingly important in oncology. Reportedly, 5 -hmC levels are reduced in several carcinomas including prostate, breast, colon and liver $[36,37]$. The current study has shown similar phenomenon in ESCC tissues. Loss of 5-hmC is likely to be common in cancers, and to play an important role in carcinogenesis.

Decreased 5-hmC levels in malignant tumors are reportedly due to mutation or reduced expression of TET1/2/3 genes [20, 22, 36, 38]. This study found that, of these three genes, only TET2 expression was lower in ESCC than in normal epithelium, and was associated with 5-hmC level. These results imply that TET2 has a central function in converting $5-\mathrm{mC}$ to $5-\mathrm{hmC}$ in esophageal epithelial cells; and that its loss decreases 5-hmC in esophageal epithelial cells, subsequently leading to ESCC development. Recently, Lian et al. has reported that $5-\mathrm{hmC}$ is lost in melanoma and rebuilding the $5-\mathrm{hmC}$ landscape in melanoma cells by reintroducing active TET2 suppresses melanoma growth and increases tumor-free survival in animal models [22]. A study of hepatocellular carcinoma (HCC) has shown that only TET1 expression was decreased in tumors relative to non-tumor tissues, indicating that TET1 has an important function in converting 5-mC to $5-\mathrm{hmC}$ in hepatocellular cells [36]. Different TET family members might participate in different types of cancers as tumor suppressors. Future studies are needed to confirm these findings, and to elucidate the mechanisms by which TET2 loss leads to reduced 5-hmC level in esophageal epithelial cells and subsequent ESCC development.

The relationship between 5-hmC levels and patient prognosis has been reported in some cancer types, with lower 5-hmC significantly associated with shorter survival in intrahepatic cholangiocarcinoma, HCC, gastric cancer, and myelodysplastic syndromes [38-42]. We also found that low 5-hmC expression was loosely associated with poor prognosis in ESCC patients (although not significantly). The exact role and molecular mechanism of 5-hmC in human cancers are still unclear. The 5-hmC as an epigenetic modifier could be a marker for both early diagnosis and prognosis of cancer. Future studies are needed to confirm the association between $5-\mathrm{hmC}$ and clinical outcome, and to examine potential mechanisms by which $5-\mathrm{hmC}$ loss affects tumor behavior.

Interestingly, 5-hmC levels were significantly associated LINE-1 methylation levels. As LINE-1 represents a major repetitive element and occupies $\sim 17 \%$ of the human genome, LINE-1 methylation levels are regarded as a surrogate marker of global DNA methylation [23]. LINE-1 methylation has been shown to be vary widely in many human neoplasms; LINE-1 hypomethylation is strongly associated with a poor prognosis in several cancer types [27, 43, 44]. As 5 -hmC is considered to be almost a sixth genomic base and possible intermediate in active DNA demethylation, our findings on the significant relationship between $5-\mathrm{hmC}$ and LINE-1 methylation levels (i.e., 5-mC level in global DNA) indicate a delicate balance between 5-mC and 5-hmC in ESCC cells.

In summary, we found that 5 -hmC expression was decreased in ESCC tissues, and was significantly associated with TET2 expression level. Taken together, TET2 reduction and subsequent 5 -hmC loss might be crucial in ESCC development and progression.

\section{MATERIALS AND METHODS}

\section{Study subjects}

We initially enrolled 107 patients with ESCC who underwent curative resection at the Kumamoto University Hospital and the National Hospital Organization Kyushu Cancer Center between March 2003 and December 2012 in this study, of whom 12 patients were excluded owing to the unavailability of adequate fresh frozen tissue specimens. Finally, 67 patients from the Kumamoto University Hospital and 28 from the National Hospital Organization Kyushu Cancer Center were included in this study. Patients were observed at 1- to 3-month intervals until death or 31 December 2013, whichever came first. Overall survival was defined as the time between the date of surgery and date of death. Written informed consent was obtained from each subject, and the study procedures were approved by the institutional review board.

\section{DNA extraction and sodium bisulfite treatment}

We extracted DNA samples from tumor and normal frozen surgical specimens, and isolated genomic DNA by standard procedures with phenol-chloroform and ethanol precipitation, using the protocol of Molecular Cloning (second edition), which was then modified with sodium bisulfite using an EpiTect Bisulfite Kit (Qiagen, Valencia, CA, USA). 


\section{Enzyme-linked immunosorbent assay (ELISA) for 5-hmC quantification}

The Quest 5-hmC'M DNA ELISA Kit (Zymo Research, Irvine, CA, USA) was used for colorimetric detection of 5-hmC, following the manufacturer's guidelines. Previous study utilized this ELISA Kit to detect the presence of 5-hmC in mammalian mitochondrial DNA [45]. Briefly, anti-5-hmC polyclonal antibody $(1 \mu \mathrm{g} / \mathrm{ml})$ and $100 \mu \mathrm{l}$ of DNA binding solution were added to a 96-well plate and incubated at $37^{\circ} \mathrm{C}$ for 60 minutes; $100 \mathrm{ng}$ of genomic DNA was added for 60 minutes, followed by $0.2 \mu \mathrm{g} / \mathrm{ml}$ of the Anti-DNA HRP antibody for 30 minutes. Absorbance was read at $450 \mathrm{~nm}$. The amount of $5-\mathrm{hmC}$ was calculated based on a standard curve generated using the kit controls.

\section{Pyrosequencing to measure LINE-1 methylation}

Genomic DNA was extracted from the tumor and modified with sodium bisulfite using an EpiTect Bisulfite Kit (Qiagen). PCR and subsequent pyrosequencing for LINE-1 were performed as previously described by Ogino et al., using the PyroMark Kit (Qiagen) [24-27]. This assay amplifies a region of the LINE-1 element (position 305-331 in accession no. X58075), which includes four $\mathrm{CpG}$ sites. The amount of $\mathrm{C}$ relative to the sum of the amounts of $\mathrm{C}$ and $\mathrm{T}$ at each $\mathrm{CpG}$ site was calculated as a percentage (i.e., $0-100 \%$ ). The average of the relative amounts of $\mathrm{C}$ in the four $\mathrm{CpG}$ sites was used as the overall LINE-1 methylation level in a given tumor. We validated our LINE-1 methylation pyrosequencing assay in the published literature [28].

\section{Quantitative real-time RT-PCR}

Total RNA was extracted from tumor or normal frozen surgical specimens using ISOGENII (Nippon Gene, Tokyo, Japan). cDNA synthesis, and quantitative reverse transcription PCR (qRT-PCR) were carried out as previously described [29]. We used the SuperScript III Transcriptor First Strand cDNA Synthesis System for RT-PCR (Invitrogen, Carlsbad, CA, USA) to synthesize cDNA, according to manufacturers' instructions, and a LightCycler 480 II instrument (Roche Diagnostics, Mannheim, Germany) to perform qRT-PCR. We used the $2^{-\Delta \Delta \mathrm{Ct}}$ method to determine differences in gene expression levels between specimens [30]. For qRT-PCR, primers were designed using the Universal Probe Library (Roche), following the manufacturer's recommendations. Expression of TET genes was normalized to that of $A R F$. Primer sequences and probes used for real-time PCR were: TET1-rt, 5'-TCTGTTGTTGTGCCTCTGGA-3' (forward) and 5'-GCCTTTAAAACTTTGGGCTTC-3' (reverse); TET2-rt, 5'-ACGCTTGGAAGCAGGAGAT-3' (forward) and 5'-AAGGCTGCCCTCTAGTTGAA-3' (reverse); TET3-rt, 5'-CGCCTCTATCCGGGAACT-3' (forward) and 5'-TCCCCGTGTAGATGACCTTC-3' (reverse); and $A R \mathrm{~F}, 5^{\prime}$-TGCTGTCCTCCTGGTGTTC-3' (forward) and 5'-CAGTTCCTGTGGCGTAGTGA-3' (reverse).

\section{Immunohistochemical staining}

Antibodies against 5-hmC (Active Motif, Carlsbad, CA, USA) were used as primary antibodies. The secondary antibody used was a ready-for-use anti-rabbit EnVision-Peroxidase system (Dako Japan Inc., Tokyo, Japan). Nuclear 5-hmC expression was recorded as negative, weak, or strong expression by an investigator (Y.B.) unaware of other data. 5-hmC-positive expression was defined as weak or strong expression in this study.

\section{Statistical methods}

For statistical analyses, we used JMP software (version 9; SAS Institute, Cary, NC). All $P$ values were two-sided. To compare means, we performed $t$-tests that assumed unequal variances. For survival analysis, we used the Kaplan-Meier method to assess survival time distribution (log-rank test).

\section{FUNDING}

This work was supported in part by the Japan Society for the Promotion of Science (JSPS) Grant-in-Aid for Scientific Research, grant number 26461953 and 15k10157.

\section{CONFLICTS OF INTEREST}

No conflict of interest exists.

\section{REFERENCES}

1. Enzinger PC, Mayer RJ. Esophageal cancer. N Engl J Med. 2003; 349:2241-52.

2. Gertler R, Stein HJ, Langer R, Nettelmann M, Schuster T, Hoefler H, Siewert J-R Feith. Long-term outcome of 2920 patients with cancers of the esophagus and esophagogastric junction: evaluation of the New Union Internationale Contre le Cancer/American Joint Cancer Committee staging system. Ann Surg. 2011; 253:689-98.

3. Rizk NP, Ishwaran H, Rice TW, Chen L-Q, Schipper PH, Kesler KA, Law S, Lerut TEMR, Reed CE, Salo JA, Scott WJ, Hofstetter WL, et al. Optimum lymphadenectomy for esophageal cancer. Ann Surg. 2010; 251:46-50.

4. Allum WH, Stenning SP, Bancewicz J, Clark PI, Langley RE. Long-term results of a randomized trial of surgery with or without preoperative chemotherapy in esophageal cancer. J Clin Oncol. 2009; 27:5062-7.

5. Fiorica F, Di Bona D, Schepis F, Licata A, Shahied L, Venturi A, Falchi AM, Craxì A, Cammà C. Preoperative 
chemoradiotherapy for oesophageal cancer: a systematic review and meta-analysis. Gut. 2004; 53:925-30.

6. Bosset JF, Gignoux M, Triboulet JP, Tiret E, Mantion G, Elias D, Lozach P, Ollier JC, Pavy JJ, Mercier M, Sahmoud T. Chemoradiotherapy followed by surgery compared with surgery alone in squamous-cell cancer of the esophagus. N Engl J Med. 1997; 337:161-7.

7. Baba Y, Watanabe M, Baba H. Review of the alterations in DNA methylation in esophageal squamous cell carcinoma. Surg Today. 2013; 43:1355-64.

8. Tahiliani M, Koh KP, Shen Y, Pastor WA, Bandukwala H, Brudno Y, Agarwal S, Iyer LM, Liu DR, Aravind L, Rao A. Conversion of 5-methylcytosine to 5-hydroxymethylcytosine in mammalian DNA by MLL partner TET1. Science. 2009; 324:930-5.

9. Ito S, D'Alessio AC, Taranova OV, Hong K, Sowers LC, Zhang Y. Role of Tet proteins in $5 \mathrm{mC}$ to $5 \mathrm{hmC}$ conversion, ES-cell self-renewal and inner cell mass specification. Nature. 2010; 466:1129-33.

10. Koh KP, Yabuuchi A, Rao S, Huang Y, Cunniff K, Nardone J, Laiho A, Tahiliani M, Sommer CA, Mostoslavsky G, Lahesmaa R, Orkin SH, et al. Tet1 and Tet 2 regulate 5-hydroxymethylcytosine production and cell lineage specification in mouse embryonic stem cells. Cell Stem Cell. 2011; 8:200-13.

11. Ito S, Shen L, Dai Q, Wu SC, Collins LB, Swenberg JA, He C, Zhang Y. Tet proteins can convert 5-methylcytosine to 5-formylcytosine and 5-carboxylcytosine. Science. 2011; 333:1300-3.

12. He Y-F, Li B-Z, Li Z, Liu P, Wang Y, Tang Q, Ding J, Jia Y, Chen Z, Li L, Sun Y, Li X, et al. Tet-mediated formation of 5-carboxylcytosine and its excision by TDG in mammalian DNA. Science. 2011; 333:1303-7.

13. Zhang H, Zhang X, Clark E, Mulcahey M, Huang S, Shi YG. TET1 is a DNA-binding protein that modulates DNA methylation and gene transcription via hydroxylation of 5-methylcytosine. Cell Res. 2010; 20:1390-3.

14. Kriaucionis S, Heintz N. The nuclear DNA base 5-hydroxymethylcytosine is present in Purkinje neurons and the brain. Science. 2009; 324:929-30.

15. Song C-X, Szulwach KE, Fu Y, Dai Q, Yi C, Li X, Li Y, Chen $\mathrm{C}-\mathrm{H}$, Zhang W, Jian X, Wang J, Zhang L, et al. Selective chemical labeling reveals the genome-wide distribution of 5-hydroxymethylcytosine. Nat Biotechnol. 2011; 29:68-72.

16. Delhommeau F, Dupont S, Della Valle V, James C, Trannoy S, Massé A, Kosmider O, Le Couedic J-P, Robert F, Alberdi A, Lécluse Y, Plo I, et al. Mutation in TET2 in myeloid cancers. N Engl J Med. 2009; 360:2289-301.

17. Ko M, Huang Y, Jankowska AM, Pape UJ, Tahiliani M, Bandukwala HS, An J, Lamperti ED, Koh KP, Ganetzky R, Liu XS, Aravind L, et al. Impaired hydroxylation of 5-methylcytosine in myeloid cancers with mutant TET2. Nature. 2010; 468:839-43.

18. Moran-Crusio K, Reavie L, Shih A, Abdel-Wahab O, Ndiaye-Lobry D, Lobry C, Figueroa ME, Vasanthakumar A, Patel J, Zhao X, Perna F, Pandey S, et al. Tet2 loss leads to increased hematopoietic stem cell self-renewal and myeloid transformation. Cancer Cell. 2011; 20:11-24.

19. Quivoron C, Couronné L, Della Valle V, Lopez CK, Plo I, Wagner-Ballon O, Do Cruzeiro M, Delhommeau F, Arnulf B, Stern M-H, Godley L, Opolon P, et al. TET2 inactivation results in pleiotropic hematopoietic abnormalities in mouse and is a recurrent event during human lymphomagenesis. Cancer Cell. 2011; 20:25-38.

20. Kudo Y, Tateishi K, Yamamoto K, Yamamoto S, Asaoka Y, Ijichi H, Nagae G, Yoshida H, Aburatani H, Koike K. Loss of 5-hydroxymethylcytosine is accompanied with malignant cellular transformation. Cancer Sci. 2012; 103:670-6.

21. Jin S-G, Kadam S, Pfeifer GP. Examination of the specificity of DNA methylation profiling techniques towards 5-methylcytosine and 5-hydroxymethylcytosine. Nucleic Acids Res. 2010; 38:e125.

22. Lian $\mathrm{CG}, \mathrm{Xu} \mathrm{Y}, \mathrm{Ceol} \mathrm{C}, \mathrm{Wu} \mathrm{F}$, Larson A, Dresser K, $\mathrm{Xu}$ W, Tan L, Hu Y, Zhan Q, Lee C-W, Hu D, et al. Loss of 5-hydroxymethylcytosine is an epigenetic hallmark of melanoma. Cell. 2012; 150:1135-46.

23. Cordaux R, Batzer MA. The impact of retrotransposons on human genome evolution. Nat Rev Genet. 2009; 10:691-703.

24. Murata A, Baba Y, Watanabe M, Shigaki H, Miyake K, Ishimoto $\mathrm{T}$, Iwatsuki $\mathrm{M}$, Iwagami $\mathrm{S}$, Sakamoto $\mathrm{Y}$, Miyamoto Y, Yoshida N, Nosho K, et al. Methylation levels of LINE-1 in primary lesion and matched metastatic lesions of colorectal cancer. Br J Cancer. 2013; 109:408-15.

25. Baba Y, Huttenhower C, Nosho K, Tanaka N, Shima K, Hazra A, Schernhammer ES, Hunter DJ, Giovannucci EL, Fuchs CS, Ogino S. Epigenomic diversity of colorectal cancer indicated by LINE-1 methylation in a database of 869 tumors. Mol Cancer. 2010; 9:125.

26. Ogino S, Kawasaki T, Nosho K, Ohnishi M, Suemoto Y, Kirkner GJ, Fuchs CS. LINE-1 hypomethylation is inversely associated with microsatellite instability and $\mathrm{CpG}$ island methylator phenotype in colorectal cancer. Int J Cancer. 2008; 122:2767-73.

27. Ogino S, Nosho K, Kirkner GJ, Kawasaki T, Chan AT, Schernhammer ES, Giovannucci EL, Fuchs CS. A cohort study of tumoral LINE-1 hypomethylation and prognosis in colon cancer. J Natl Cancer Inst. 2008; 100:1734-8.

28. Iwagami S, Baba Y, Watanabe M, Shigaki H, Miyake K, Ida S, Nagai Y, Ishimoto T, Iwatsuki M, Sakamoto Y, Miyamoto Y, Baba H. Pyrosequencing assay to measure LINE-1 methylation level in esophageal squamous cell carcinoma. Ann Surg Oncol. 2012; 19:2726-32. 
29. Baba Y, Watanabe M, Murata A, Shigaki H, Miyake K, Ishimoto T, Iwatsuki M, Iwagami S, Yoshida N, Oki E, Sakamaki K, Nakao M, et al. LINE-1 hypomethylation, DNA copy number alterations, and CDK6 amplification in esophageal squamous cell carcinoma. Clin Cancer Res. 2014; 20:1114-24

30. Mima K, Okabe H, Ishimoto T, Hayashi H, Nakagawa S, Kuroki H, Watanabe M, Beppu T, Tamada M, Nagano O, Saya H, Baba H. CD44s regulates the TGF- $\beta$-mediated mesenchymal phenotype and is associated with poor prognosis in patients with hepatocellular carcinoma. Cancer Res. 2012; 72:3414-23.

31. Ficz G, Branco MR, Seisenberger S, Santos F, Krueger F, Hore TA, Marques CJ, Andrews S, Reik W. Dynamic regulation of 5-hydroxymethylcytosine in mouse ES cells and during differentiation. Nature. 2011; 473:398-402.

32. Thalhammer A, Hansen AS, El-Sagheer AH, Brown T, Schofield CJ. Hydroxylation of methylated CpG dinucleotides reverses stabilisation of DNA duplexes by cytosine 5-methylation. Chem Commun (Camb). 2011; 47:5325-7.

33. Valinluck V, Sowers LC. Endogenous cytosine damage products alter the site selectivity of human DNA maintenance methyltransferase DNMT1. Cancer Res. 2007; 67:946-50.

34. Zhang $\mathrm{P}, \mathrm{Su}$ L, Wang Z, Zhang S, Guan J, Chen Y, Yin Y, Gao F, Tang B, Li Z. The involvement of 5-hydroxymethylcytosine in active DNA demethylation in mice. Biol Reprod. 2012; 86:104.

35. Valinluck V, Tsai H-H, Rogstad DK, Burdzy A, Bird A, Sowers LC. Oxidative damage to methyl-CpG sequences inhibits the binding of the methyl-CpG binding domain (MBD) of methyl-CpG binding protein 2. Nucleic Acids Res. 2004; 32:4100-8.

36. Yang H, Liu Y, Bai F, Zhang J-Y, Ma S-H, Liu J, Xu Z-D, Zhu H-G, Ling Z-Q, Ye D, Guan K-L, Xiong Y. Tumor development is associated with decrease of TET gene expression and 5-methylcytosine hydroxylation. Oncogene. 2013; 32:663-9.

37. Haffner MC, Chaux A, Meeker AK, Esopi DM, Gerber J, Pellakuru LG, Toubaji A, Argani P, Iacobuzio-Donahue C, Nelson WG, Netto GJ, De Marzo AM, et al. Global 5-hydroxymethylcytosine content is significantly reduced in tissue stem/progenitor cell compartments and in human cancers. Oncotarget. 2011; 2:627-37.

38. Liu C, Liu L, Chen X, Shen J, Shan J, Xu Y, Yang Z, Wu L, Xia F, Bie P, Cui Y, Bian X, et al. Decrease of 5-hydroxymethylcytosine is associated with progression of hepatocellular carcinoma through downregulation of TET1. PLoS One. 2013; 8:e62828.

39. Dong Z-R, Zhang C, Cai J-B, Zhang P-F, Shi G-M, Gao D-M, Sun H-C, Qiu S-J, Zhou J, Ke A-W, Fan J. Role of 5-hydroxymethylcytosine level in diagnosis and prognosis prediction of intrahepatic cholangiocarcinoma. Tumour Biol. 2015; 36:2763-71.

40. Liu W-R, Tian M-X, Jin L, Yang L-X, Ding Z-B, Shen Y-H, Peng Y-F, Zhou J, Qiu S-J, Dai Z, Fan J, Shi Y-H. High expression of 5-hydroxymethylcytosine and isocitrate dehydrogenase 2 is associated with favorable prognosis after curative resection of hepatocellular carcinoma. J Exp Clin Cancer Res. 2014; 33:32.

41. Yang Q, Wu K, Ji M, Jin W, He N, Shi B, Hou P. Decreased 5-hydroxymethylcytosine $(5-\mathrm{hmC})$ is an independent poor prognostic factor in gastric cancer patients. J Biomed Nanotechnol. 2013; 9:1607-16.

42. Liu X, Zhang G, Yi Y, Xiao L, Pei M, Liu S, Luo Y, Zhong H, Xu Y, Zheng W, Shen J. Decreased 5-hydroxymethylcytosine levels are associated with TET2 mutation and unfavorable overall survival in myelodysplastic syndromes. Leuk Lymphoma. 2013; 54:2466-73.

43. Shigaki H, Baba Y, Watanabe M, Murata A, Iwagami S, Miyake K, Ishimoto T, Iwatsuki M, Baba H. LINE-1 hypomethylation in gastric cancer, detected by bisulfite pyrosequencing, is associated with poor prognosis. Gastric Cancer. $2013 ; 16: 480-7$.

44. Iwagami S, Baba Y, Watanabe M, Shigaki H, Miyake K, Ishimoto T, Iwatsuki M, Sakamaki K, Ohashi Y, Baba H. LINE-1 hypomethylation is associated with a poor prognosis among patients with curatively resected esophageal squamous cell carcinoma. Ann Surg. 2013; 257:449-55.

45. Shock LS, Thakkar PV, Peterson EJ, Moran RG, Taylor SM. DNA methyltransferase 1, cytosine methylation, and cytosine hydroxymethylation in mammalian mitochondria. Proc Natl Acad Sci U S A. 2011; 108:3630-5. 